Sar di ne procal ci toni $n$ am no- termi nal cl eavage pept i de has a di fferent acti on fromcal ci toni $n$ and promot es osteobl ast i $c$ act i vity in the scal es of gol df i sh

\begin{tabular}{|c|c|}
\hline 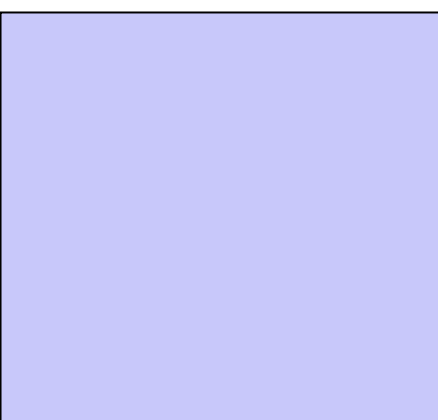 & $\begin{array}{l}\text { Kase Yoi chi, I kar i Takahi ro, Seki guchi Toshi o, } \\
\text { Sat o Nasayuki, Ogi so Shouzo, Kawada Tsuyoshi, } \\
\text { Mat subar a Shi n, Sat ake Honoo, Sasayana Yui chi, } \\
\text { Endo Nasat o, Ki tamura Kei - i chi ro, Hat t or i } \\
\text { At suhi ko, Wat anabe Takushi X., Nar uyama } \\
\text { Yusuke, Wat anabe Yoshi nar i, Funahashi } \\
\text { Hi sayuki, Kanbegawa Aki ra, Suzuki Nobuo }\end{array}$ \\
\hline $\begin{array}{l}\text { j our nal or } \\
\text { publ i cat i on titl e }\end{array}$ & $\begin{array}{l}\text { Compar at i ve Bi ochemi st ry and Physi ol ogy - Part } \\
\text { A : Mbl ecul ar and I nt egr at i ve Physi ol ogy }\end{array}$ \\
\hline vol une & 211 \\
\hline page $r$ ange & 77- 83 \\
\hline year & 2017-09-01 \\
\hline URL & ht t p: //hdl . handl e. net /2297/48459 \\
\hline
\end{tabular}




\section{Sardine procalcitonin amino-terminal cleavage peptide has a different action from calcitonin and promotes osteoblastic activity in the scales of goldfish}

Yoichi Kase ${ }^{1}$, Takahiro Ikari $^{1}$, Toshio Sekiguchi ${ }^{1}$, Masayuki Sato ${ }^{1}$, Shouzo Ogiso ${ }^{1}$, Tsuyoshi Kawada $^{2}$, Shin Matsubara ${ }^{2}$, Honoo Satake ${ }^{2}$, Yuichi Sasayama ${ }^{1}$, Masato Endo ${ }^{3}$, Kei-ichiro Kitamura $^{4}$, Atsuhiko Hattori ${ }^{5}$, Takushi X. Watanabe $^{6}$, Yusuke Maruyama ${ }^{5}$, Yoshinari Watanabe $^{7}$, Hisayuki Funahashi ${ }^{8}$, Akira Kambegawa ${ }^{9}$ and Nobuo Suzuki ${ }^{1^{*}}$

${ }^{1}$ Noto Marine Laboratory, Institute of Nature and Environmental Technology, Kanazawa University, Noto-cho, Ishikawa 927-0553, Japan

${ }^{2}$ Bioorganic Research Institute, Suntory Foundation for Life Sciences, 8-1-1, Seikadai, Seikacho, Soraku-gun, Kyoto 619-0284, Japan

${ }^{3}$ Graduate School of Marine Science and Technology, Tokyo University of Marine Science and Technology, Minato-ku, Tokyo 108-8477, Japan

${ }^{4}$ Department of Clinical Laboratory Science, Graduate School of Medical Science, Kanazawa University, Kanazawa, Ishikawa 920-0942, Japan

${ }^{5}$ Department of Biology, College of Liberal Arts and Sciences, Tokyo Medical and Dental University, Ichikawa, Chiba 272-0827, Japan

${ }^{6}$ Peptide Institute Inc., Osaka 567-0085, Japan

${ }^{7}$ Organization of Frontier Science and Innovation, Kanazawa University, Kakuma, Ishikawa 920-1192, Japan

${ }^{8}$ Department of Anatomy, Showa University School of Medicine, Shinagawa-ku, Tokyo 1428555, Japan

${ }^{9}$ Kambegawa Laboratory, Tokyo 201-0013, Japan

*Correspondence to: Dr. Nobuo. Suzuki, Noto Marine Laboratory, Institute of Nature and Environmental Technology, Kanazawa University, Ogi, Noto-cho, Ishikawa 927-0553, Japan.

Tel.: 81-768-74-1151; Fax 81-768-74-1644;

e-mail: nobuos@staff.kanazawa-u.ac.jp 


\section{ABSTRACT}

The nucleotide sequence of a sardine preprocalcitonin precursor has been determined from their ultimobranchial glands in the present study. From our analysis of this sequence, we found that sardine procalcitonin was composed of procalcitonin amino-terminal cleavage peptide (N-proCT) (53 amino acids), CT (32 amino acids), and procalcitonin carboxylterminal cleavage peptide (C-proCT) (18 amino acids). As compared with C-proCT, NproCT has been highly conserved among teleosts, reptiles, and birds, which suggests that NproCT has some bioactivities. Therefore, both sardine N-proCT and sardine CT were synthesized, and their bioactivities for osteoblasts and osteoclasts were examined using our assay system with goldfish scales that consisted of osteoblasts and osteoclasts. As a result, sardine $\mathrm{N}$-proCT $\left(10^{-7} \mathrm{M}\right)$ activated osteoblastic marker enzyme activity, while sardine CT did not change. On the other hand, sardine CT $\left(10^{-9}\right.$ to $\left.10^{-7} \mathrm{M}\right)$ suppressed osteoclastic marker enzyme activity, although sardine N-proCT did not influence enzyme activity. Furthermore, the mRNA expressions of osteoblastic markers such as type 1 collagen and osteocalcin were also promoted by sardine $\mathrm{N}$-proCT $\left(10^{-7} \mathrm{M}\right)$ treatment; however, sardine CT did not influence their expressions. The osteoblastic effects of N-proCT lack agreement. In the present study, we can evaluate exactly the action for osteoblasts because our scale assay system is very sensitive and it is a co-culture system for osteoblasts and osteoclasts with calcified bone matrix. Both CT and N-proCT seem to influence osteoblasts and osteoclasts and promote bone formation by different actions in teleosts. 
Keywords: Procalcitonin amino-terminal cleavage peptide; Calcitonin; Osteoblasts; Osteoclasts; Japanese sardine; Scales

Abbreviations: alkaline phosphatase, ALP; Calcitonin, CT; procalcitonin carboxyl-terminal cleavage peptide, C-proCT; procalcitonin amino-terminal cleavage peptide, N-proCT; paranitrophenol, pNP; tartrate-resistant acid phosphatase, TRAP; rapid amplification of cDNA ends, RACE; reverse phase high performance liquid chromatography, RP-HPLC; ultimobranchial gland, UBG 


\section{INTRODUCTION}

Calcitonin (CT) is composed of 32 amino acid residues and functions as a hypocalcemic hormone resulting from the suppression of osteoclastic activity in mammals (Azria, 1989). Furthermore, in teleosts as well as mammals, it has been demonstrated that CT suppresses osteoclastic activity in both freshwater and seawater teleosts (Suzuki et al., 2000; Sekiguchi et al., 2009). CT is mainly synthesized in the C-cell of the thyroid gland in mammals and the ultimobranchial gland (UBG) in non-mammalian vertebrates (Sasayama, 1999). In the process of CT production, this hormone is first generated in the form of a preprocalcitonin precursor, which is subsequently cleaved into 3 peptides: procalcitonin amino-terminal cleavage peptide (N-proCT), CT, and procalcitonin carboxyl-terminal cleavage peptide (CproCT) in salmon, chickens, rats, and humans (Burns et al., 1989a; 1989b). In neoplastic C cell cultures, it has been reported that N-proCT and CT concentrations are nearly equimolar in both cellular extracts and basal media (Burns et al., 1989a). These facts strongly suggest that N-proCT has some bioactivities.

Until now, there has not been agreement in the literature regarding whether N-proCT has osteoblastic effects. Namely, human N-proCT had no mitogenic activity on osteoblasts or preosteoblasts in rats (Guenther and Fleisch, 1991) and has no accelerating effects on the mitosis and cell differentiation of human osteoblasts (Hassager et al., 1991). In contrast, Burns et al. (1989b) found that nanomolar concentrations of N-proCT (treatment duration 20-22 hr) were mitogenic for a human osteosarcoma cell line.

On the other hand, we previously determined the peptide sequence of the CT from UBGs of Japanese sardines (Sardinops melanostictus) using reversed phase high-performance liquid 
chromatography (RP-HPLC) (Suzuki et al., 1994). The hypocalcemic activity of synthetic sardine CT was examined by comparing it with that of synthetic salmon CT using a rat bioassay. We found that hypocalcemic activity in sardine CT was more than double that in salmon CT (Suzuki et al., 1994). Therefore, sardine N-proCT may have high activity in osteoblasts as sardine CT has high activity in calcium metabolism. However, in general, sardine is difficult to keep long term in aquarium, although this fish was easily collected in Japan. Therefore, this species is not suitable for physiological experiments. To analyze the bioactivity of both CT and N-proCT, we have developed an original in vitro assay system with goldfish and have previously shown that goldfish CT suppressed osteoclastic activity in the scales of goldfish (Carassius auratus) (Suzuki et al., 2000; Suzuki et al., 2008; Sekiguchi et al., 2009). Furthermore, the osteoclast-activating hormone, parathyroid hormone, acted on osteoblasts and osteoclasts and then induced active-type osteoclasts (multinucleated osteoclasts) in goldfish (Suzuki et al., 2011). Therefore, our scale in vitro bioassay with goldfish is suitable for the elucidation of hormonal function.

In the present study, we determined the full-length sequence of the sardine preprocalcitonin precursor from their UBGs using 5' and 3' rapid amplification of cDNA ends (RACE) methods. Furthermore, both sardine N-proCT and sardine CT were synthesized, and their bioactivities for osteoblasts and osteoclasts were examined using our original assay system with goldfish scales.

\section{MATERIALS AND METHODS}

\subsection{Animals}


Japanese sardines (Sardinops melanostictus) were purchased from Choshi’s Fishermen’s Cooperative Association. The fish were used to determine a preprocalcitonin precursor.

Goldfish (Carassius auratus), purchased from a commercial source (Higashikawa Fish Farm, Yamatokoriyama, Japan), were artificially fertilized from a female and a male goldfish (20-30 g) at the Graduate School of Marine Science and Technology, Tokyo University of Marine Science and Technology. Fish were fed a commercial pellet diet every morning and were kept in tap water at $26^{\circ} \mathrm{C}$. Growing fish of approximately $20 \mathrm{~g}$ of body weight were moved to Noto Marine Laboratory at Kanazawa University and used for the in vitro experiments.

All experimental procedures were conducted in accordance with the Guide for the Care and Use of Laboratory Animals prepared by Kanazawa University.

\subsection{Sequencing of a preprocalcitonin precursor from sardine UBGs}

UBGs were removed from Japanese sardines (Sardinops melanostictus) and kept in RNAlater ${ }^{\circledR}$ (Sigma-Aldrich, St. Louis, MO, USA). Total RNAs were extracted from the UBGs using a total RNA isolation kit (NucleoSpin RNA II, TaKaRa Bio Inc., Otsu, Japan). The full-length sequence of sardine preprocalcitonin was determined by RACE using the GeneRacer ${ }^{\circledR}$ Kit (Life Technologies, Tokyo, Japan). The first-strand cDNA was reverse transcribed from $1 \mu \mathrm{g}$ total RNA using an oligo-dT-adapter primer. The 3' RACE genespecific primers (5'-GACTCTGAAAGACTGCGCCTTTTTCC-3') were designed according to the sequence of a previous partial cloning (Suzuki et al., 1999). PCR fragments were obtained using a 3' RACE primer and adaptor primer provided from a kit, and were 
directionally sequenced by the ABI PRISM ${ }^{\mathrm{TM}} 3130$ Genetic Analyzer using a 3' RACE primer. Next, 5' RACE was performed using a 5' RACE primer (5'GACTCTGAAAGACTGCGCCTTTTTCC-3') and an adapter primer. The PCR product was subcloned using the pGEM-T Easy (Promega, Madison, Wisconsin, USA) and was sequenced with the ABI PRISM ${ }^{\mathrm{TM}} 3130$ Genetic Analyzer using plasmid universal primers.

\subsection{Molecular phylogenetic analysis}

Molecular phylogenetic analysis was performed with modification of the previous study (Sekiguchi et al., 2016). In brief, the amino acid sequences were aligned using the ClustalW program's MEGA 6.06 software (Tamura et al., 2013). After manually removing gaps, alignments were calculated to construct unrooted phylogenetic trees using the neighbor-joining method with MEGA 6.06 software. Moreover, the bootstrap value was estimated by 1000 pseudoreplications using MEGA 6.06 software. The sequences of the CT precursors used are as follows: Japanese medaka, NP_001098365; fugu, CAC81278; Atlantic salmon, NP_001135058; green sea turtle, EMP38282; American alligator, XP_006275102; rock pigeon, EMC88082; chicken, ABY65359; African ostrich, XP_009683015; turkey, XP_003206284; platypus, ENSOANP00000017830; Tasmanian devil, XP_003773616; nine-banded armadillo, XP_004472573; cattle, NP_001137209; domestic cat, BAO79719; horse, AAF72526; human, AAA58403; rhesus monkey, EHH23079; house mouse, P70160; and Norway rat, AAA40849.

\subsection{Peptide synthesis}

Sardine CT was a gift from the Peptide Institute Inc. (Osaka, Japan). Sardine N-proCT was synthesized by a solid-phase peptide synthesizer (CS36X: CSBio Co. Inc., Menlo Park, CA, USA) using the Fmoc method, in accordance with the manufacturer's instructions. In 
brief, 0.25 mmol Fmoc-NH-SAL-PEG resin and $1 \mathrm{mmol}$ of each Fmoc amino acid were used in the reaction. Peptides collected from the reacted resin were separated using a RP-HPLC with a C18 column (Shimadzu LabSolutions: Shimadzu Co., Kyoto, Japan), and the fraction corresponding to the main peak was collected. Peptides in the fraction were measured using mass spectrometry (Ultraflex III: Bruker Daltonics Inc., Billerica, MA, USA), showing a single peak corresponding to the appropriate sardine N-proCT molecular weight.

2.5. Effects of sardine $C T$ and sardine $N$-proCT on scale osteoblastic and osteoclastic activities using the cultured scales of goldfish

Scales were collected from goldfish under anesthesia in $0.03 \%$ ethyl 3 -aminobenzoate methanesulfonic acid salt (Sigma-Aldrich, Inc., St. Louis, MO, USA); aeration was provided with an electric motor. Using these scales, we examined the influences of both sardine CT and sardine N-proCT on osteoblasts and osteoclasts with alkaline phosphatase (ALP) and tartrateresistant acid phosphatase (TRAP) as markers (Suzuki et al., 2000; Suzuki and Hattori, 2002). These scales were incubated for 6 h in Leibovitz's L-15 Medium (Thermo Fisher Scientific Inc., Grand Island, NY, USA) containing a 1\% penicillin-streptomycin mixture (Thermo Fisher Scientific Inc.) supplemented with each peptide $\left(10^{-9}, 10^{-8}\right.$, and $\left.10^{-7} \mathrm{M}\right)$.

The methods for measuring ALP and TRAP activities were as follows. After incubation, the medium of each well was removed. Then, each well was washed with phosphate buffered saline. Thereafter, an aliquot of $100 \mu \mathrm{l}$ of an alkaline buffer (100 mM Tris-HCl, pH 9.5; $1 \mathrm{mM}$ $\mathrm{MgCl}_{2}$ ) or an acid buffer (0.1 M sodium acetate, including $20 \mathrm{mM}$ tartrate, $\mathrm{pH}$ 5.3) was added to each well. This microplate was immediately frozen at $-80^{\circ} \mathrm{C}$ and then kept at $-20^{\circ} \mathrm{C}$ until analysis. The next, an aliquot of $100 \mu \mathrm{l}$ of $20 \mathrm{mM}$ para-nitrophenyl phosphate in an alkaline or acid buffer was then added to each microplate well with a melted alkaline or acid buffer 
solution. This plate was incubated at $23^{\circ} \mathrm{C}$ for 60 min while being shaken. After incubation, the reaction was stopped by adding $50 \mu \mathrm{l}$ of $3 \mathrm{~N} \mathrm{NaOH}$. The $150 \mu \mathrm{l}$ of a reacted solution was transferred to a new plate, and the absorbance was measured at $405 \mathrm{~nm}$. The absorbance was converted into the amount of produced para-nitrophenol (pNP) using a standard curve for pNP.

After measuring both ALP and TRAP activities, the surface area of the scales was calculated using Image J. Thereafter, ALP and TRAP activities were normalized to the surface area $\left(\mathrm{mm}^{2}\right)$ of each scale (Suzuki et al., 2009).

2.6. Effects of sardine $C T$ and sardine $N$-proCT on scale osteoblastic marker mRNA expressions using cultured goldfish scales

Scales were collected from goldfish under anesthesia with $0.03 \%$ ethyl 3 -aminobenzoate methanesulfonic acid salt (Sigma-Aldrich). To examine changes in genes expressed in osteoblasts that responded to sardine CT and sardine N-proCT (each $10^{-7} \mathrm{M}$ ), these scales were incubated for $6 \mathrm{~h}$ in Leibovitz's L-15 medium (Thermo Fisher Scientific Inc.) containing a 1\% penicillin-streptomycin mixture (Thermo Fisher Scientific Inc.). After incubation, the scales were frozen at $-80^{\circ} \mathrm{C}$ for mRNA analysis.

Total RNAs were prepared from goldfish scales using a total RNA isolation kit for fibrous tissue (QIAGEN GmbH, Hilden, Germany). Complementary DNA synthesis was performed using a kit (QIAGEN GmbH). To examine the osteoblastic activation of scales by sardine CT and sardine N-proCT treatment, the mRNA expression of osteoblastic markers (type 1 collagen and osteocalcin) were examined. Gene-specific primers for type 1 collagen (sense: 5’-TGCAACCAGGATGCCATCAA-3'; antisense: 5'ATGAGGCGCAGGAAGGTGAG-3’) and for osteocalcin (sense: 5'- 
ATGCCTGAGCGCAGGTCTTC-3’; $\quad$ antisense: 5'-CACAGGCCAGGTTTGCTTCA-3’) (Thamamongood et al., 2012) were used. The amplification of EF-1 $\alpha$ cDNA using a primer set (sense: 5'-ATTGTTGCTGGTGGTGTTGG-3'; antisense: 5’GGCACTGACTTCCTTGGTGA-3’) (AB979720) was performed. The PCR amplification was analyzed using real-time PCR apparatus (Mx3000p, Agilent Technologies, Santa Clara, CA, USA) (Suzuki et al. 2011; Thamamongood et al., 2012). The annealing temperature of type 1 collagen, osteocalcin, and EF- $1 \alpha$ was $60^{\circ} \mathrm{C}$. Type 1 collagen and osteocalcin mRNA levels were normalized to the EF-1 $\alpha$ mRNA level.

\subsection{Statistical analysis}

All results are expressed as the means \pm SE. The statistical significance between the control and the experimental group was assessed by Student's t-test (in vitro cell activity experiment) or paired $t$-test (osteoblastic marker mRNA expression). In all cases, the selected significance level was $p<0.05$.

\section{RESULTS}

\subsection{Sequencing of the preprocalcitonin precursor from sardine UBGs}

The sequence of the sardine preprocalcitonin precursor was obtained from the RNA of their UBGs using RACE methods. The sardine preprocalcitonin precursor was composed of 134 amino acid residues that included signal peptides (25 amino acids) (Fig. 1). We predicted the signal peptide sequence by using the program, SignalP 4 (Petersen et al., 2011). Sardine 
procalcitonin was composed of N-proCT (53 amino acids), CT (32 amino acids), and CproCT (18 amino acids) (Fig. 1).

These vertebrate N-proCTs have some common features (Fig. 2). These features are summarized as follows: 1) The first amino acid residue is mostly Ala (Thr or Val in some cases); 2) there is no Cys residue in the sequence of N-proCT; 3) eight residues (Lys ${ }^{4}, \mathrm{Leu}^{17}$, $\mathrm{Leu}^{25}, \mathrm{Leu}^{26}, \mathrm{Ala}^{28}, \mathrm{Gln}^{35}$, $\mathrm{Ser}^{59}$, and $\mathrm{Asp}^{61}$ ) are well conserved in all N-proCTs; 4) insertion/deletion points are present in the sequence of N-proCT from the 9th to the 11th, from the 46th to the 50th, and from the 54th to the 58th positions.

As with CT, N-proCT has been highly conserved among vertebrates, as compared with CproCT (Table 1). Namely, the amino acid sequence of sardine CT was more like that of teleosts, reptiles, and birds (93.8-96.9\%) than that of Marsupialia (platypus: 93.8\%; Tasmanian devil: 87.5\%), and it is different from that of Placentalia (50.0-75.0\%) (Table 1). Also, the predicted amino acid sequence of sardine N-proCT was more conserved among teleosts, reptiles, and birds (78.2-85.5\%) than in Marsupialia (platypus 66.7\%; Tasmanian devil: 69.6\%) and Placentalia (48.3-63.2\%) (Table 1).

\subsection{Phylogenetic analysis of sardine $C T$ and sardine $N$-proCT}

The phylogenetic tree was constructed from known CTs and N-proCTs, together with sardine CT and sardine N-proCT. The form of the molecular phylogenetic tree of CTs was similar to that of N-proCTs (Fig. 3). Both sardine CT and sardine N-proCT are grouped into the clade that includes non-mammalian vertebrates and Marsupialia with the high support of bootstrap values. Sardine N-proCT was classified into the same group with Atlantic salmon, Japanese medaka, and fugu. 
3.3. Effects of sardine CT and sardine N-proCT on scale osteoblastic and osteoclastic activities using cultured goldfish scales

The bioactivities of both sardine CT and sardine N-proCT were examined using our assay system with goldfish scales. The results are indicated in Figure 4.

Sardine N-proCT $\left(10^{-7} \mathrm{M}\right)$ activated ALP (osteoblastic marker enzyme) activity in the scales of goldfish, although sardine CT $\left(10^{-9}\right.$ to $\left.10^{-7} \mathrm{M}\right)$ did not influence ALP activity. In both peptides $\left(10^{-9}\right.$ and $\left.10^{-8} \mathrm{M}\right)$, ALP activity did not change significantly.

In the case of TRAP activity, sardine CT $\left(10^{-9}\right.$ to $\left.10^{-7} \mathrm{M}\right)$ responded to osteoclasts and suppressed TRAP activity in a dose-dependent manner; however, sardine N-proCT did not change their activities (Fig. 5).

3.4. Effects of sardine CT and sardine $N$-proCT on scale osteoblastic marker mRNA expressions using cultured goldfish scales

To confirm the promotive action of sardine N-proCT in osteoblasts, we examined osteoblastic marker mRNA expression in cultured scales.

The results are indicated in Figure 6. The mRNA expressions of osteoblastic markers such as type 1 collagen and osteocalcin were promoted by sardine $\mathrm{N}$-proCT $\left(10^{-7} \mathrm{M}\right)$ treatment; however, sardine CT did not influence their expressions.

\section{DISCUSSION}

Using RACE methods, we determined the full length of the sardine preprocalcitonin precursor (Fig. 1). Our results indicate that sardine procalcitonin was composed of N-proCT 
(53 amino acids), CT (32 amino acids), and C-proCT (18 amino acids) (Fig. 1). The amino acid sequences of $19 \mathrm{~N}$-proCTs, including sardine N-proCT, were calculated by the neighborjoining method using MEGA 6.06 software (Tamura et al., 2013). The molecular phylogenetic tree of CTs and N-proCTs revealed that these peptides are discriminated between mammalian and non-mammalian with high bootstrap values (Fig. 3). Interestingly, the CTs and N-proCTs of Marsupialia, which are primitive mammals, are located in the same clade formed by those of non-mammalian vertebrates (Fig. 3). The similarity of sardine N-proCT to that of Marsupialia (platypus: 66.7\%; Tasmanian devil: 69.6\%) was different from that to Placentalia (48.3-63.2\%) (Table 1). Similar results were obtained for CTs. Sardine CT was more similar to that of Marsupialia (platypus: 93.8\%; Tasmanian devil: 87.5\%) than to that of Placentalia (50.0-75.0\%) (Table 1). The sequence similarity was also supported by phylogenetic analysis.

Next, the bioactivity of sardine N-proCTs was examined with a goldfish scale in vitro assay system and compared with that of sardine CT. As a result, we are the first to demonstrate that sardine N-proCT $\left(10^{-7} \mathrm{M}\right)$ activated osteoblastic marker enzyme activity; however, sardine CT did not change (Fig. 4). On the other hand, sardine CT (10-7 to $\left.10^{-9} \mathrm{M}\right)$ suppressed osteoclastic marker enzyme activity, although sardine N-proCT did not influence enzyme activity (Fig. 5). In addition, osteoblastic marker (type 1 collagen and osteocalcin) mRNA expression was promoted by sardine N-proCT $\left(10^{-7} \mathrm{M}\right)$ treatment; however, sardine CT did not influence their expressions (Fig. 6). Our obtained bioactivity of sardine N-proCT was supported by a previous report that human N-proCT has mitogenic action in a human osteosarcoma cell line (Burns et al., 1989b). Furthermore, Burns et al. (1989a) reported that in rats, thyroidal levels of CT and N-proCT increase in parallel in vivo when C-cell hyperplasia is induced by a high-fat diet. In neoplastic C-cell cultures, also, N-proCT and CT 
concentrations are nearly equimolar in both cellular extracts and basal medium; dexamethasone increases both the cellular and secreted concentration of these peptides (Burns et al., 1989a). Judging from the report of Burns et al. (1989a, 1989b), mammalian N-proCT appears to be present in equimolar amounts and coordinately regulated with CT both in vivo and in vitro. In vertebrates, including rats, humans, and teleosts, $\mathrm{N}$-proCT might function in osteoblasts and regulate bone metabolism.

In the reproductive period, the plasma calcium level in female teleosts increases remarkably (Watts et al., 1975; Yamauchi et al., 1978; Norberg et al., 1989; Suzuki et al., 2004; Guerreiro et al., 2007). The candidate for this hypercalcemic hormone is estrogen. In female teleosts, estrogen promotes the synthesis of vitellogenin, which is a major component of egg protein and a calcium-binding protein (Kwon et al., 1993; Tinsley, 1985). At the same time, estrogen promotes calcium resorption from scales by activating osteoclasts (Persson et al., 1995; Suzuki et al., 2000; Suzuki and Hattori, 2003). In estrogen-injected goldfish, scale TRAP and ALP activities (Suzuki and Hattori, 2003) and plasma calcium levels (Suzuki et al., 2003) increased. In estrogen-injected goldfish, we demonstrated that estrogen promoted CT secretion and that estrogen directly acts on the UBG since the estrogen receptor was detected in the UBG (Suzuki et al., 2004). In teleost reproduction, CT suppresses the excess degradation of calcified tissues (Suzuki et al., 2004). In this period, N-proCT might be effective in bone formation. Namely, both CT and N-proCT cleaved from a preprocalcitonin precursor seem to influence osteoblasts and osteoclasts and protect from excess bone resorption by different actions.

We can detect bioactivities of $\mathrm{N}$-proCT because our scale assay system in the present study is very sensitive. In addition, parathyroid hormone and prostaglandin $E_{2}$ function in 
osteoblasts and osteoclasts of scales (Suzuki et al., 2011; Omori et al., 2012). The sensitivity of our assay system may be caused by the coexistence of osteoblasts, osteoclasts, and bone matrix (Bereiter-Hahn and Zylberberg, 1993; Suzuki et al., 2000; Yoshikubo et al., 2005; Redruello et al., 2005; Suzuki et al., 2007; Ohira et al., 2007; Azuma et al., 2007; Suzuki et al., 2008). The mechanism of N-proCT for osteoblasts has not yet been elucidated, although we discovered a new function of $\mathrm{N}$-proCT on osteoblasts in teleosts. We believe that $\mathrm{N}$-proCT binds to a novel receptor in osteoblasts. Therefore, using our scale in vitro assay system with goldfish, we are planning to investigate the detailed mechanism of N-proCT on osteoblasts.

\section{ACKNOWLEDGMENTS}

This study was supported in part by grants to N.S. (Grant-in-Aid for Scientific Research [C] No. 16K07871 by JSPS), to Y.T. (Grant-in-Aid for Scientific Research [B] No. 24310046 by JSPS), to A.H. (Grant-in-Aid for Scientific Research [C] No. 24570068 by JSPS), to T.S. (Scientific Research [C] No. 15K07126 by JSPS), and to K.K. (Scientific Research [C] No. 15K01705 by JSPS). This work was partly supported by the cooperative research program of the Institute of Nature and Environmental Technology, Kanazawa University, Accept Number 17018 and by The Salt Science Research Foundation (No.1731).

\section{References}

Azria, M., 1989. In: The calcitonins: Physiology and Pharmacology, Karger, Basel.

Azuma, K., Kobayashi, M., Nakamura, M., Suzuki, N., Yashima, S., Iwamuro, S., Ikegame, M., Yamamoto, T., Hattori, A., 2007. Two osteoclastic markers expressed in multinucleate 
osteoclasts of goldfish scales. Biochem. Biophys. Res. Commun. 362, 594-600.

Bereiter-Hahn, J., Zylberberg, L., 1993. Regeneration of teleost fish scale. Comp. Biochem. Physiol. Part A, 105, 625-641.

Burns, D.M., Birnbaum, R.S., Roos, B.A., 1989a. A neuroendocrine peptide derived from the amino-terminal half of rat procalcitonin. Mol. Endocrinol., 3, 140-147.

Burns, D.M., Forstrom, J.M., Friday, K.E., Howard, G.A., Roos, B.A. 1989b. Procalcitonin's amino-terminal cleavage peptide is a bone-cell mitogen. Proc. Natl. Acad. Sci. USA., 86, 9519-9523.

Guenther, H.L., Fleisch, H., 1991. The procalcitonin amino-terminal cleavage peptide (NproCT) lacks biological activity on normal clonal rat osteoblastic and preosteoblastic cells in vitro. Calcif. Tissue Int., 49, 138-140.

Guerreiro, P.M., Renfro, J.L., Power, D.M., Canario, A.V.M., 2007. The parathyroid hormone family of peptides: structure, tissue distribution, regulation, and potential functional roles in calcium and phosphate balance in fish. Am. J. Physiol. Regul. Integr. Comp. Physiol., 292, R679-R696.

Hassager, C., Bonde, S.K., Anderson, M.A., Rink, H., Spelsberg, T.C., Riggs, B.L., 1991. Procalcitonin $\mathrm{NH}_{2}$-terminal cleavage peptide has no mitogenic effect on normal human osteoblast-like cells. J. Bone Miner. Res., 6, 489-493.

Kwon, H.C., Hayashi, S., Mugiya, Y., 1993. Vitellogenin induction by estradiol-17 $\beta$ in primary hepatocyte culture in the rainbow trout, Oncorhynchus mykiss. Comp. Biochem. Physiol. Part B, 104, 381-386. 
Norberg, B., Björnsson, B.Th., Brown, C.L., Wichardt, U.-P., Deftos, L.J., Haux, C., 1989. Changes in plasma vitellogenin, sex steroids, calcitonin, and thyroid hormones related to sexual maturation in female brown trout (Salmo trutta). Gen. Comp. Endocrinol., 75, 316326.

Ohira, Y., Shimizu, M., Ura, K., Takagi, Y., 2007. Scale regeneration and calcification in goldfish Carassius auratus: quantitative and morphological processes. Fisheries Sci., 73, 46-54.

Omori, K., Wada, S., Maruyama, Y., Hattori, A., Kitamura, K., Sato, Y., Nara, M., Funahashi, H., Yachiguchi, K., Hayakawa, K., Endo, M., Kusakari, R., Yano, S., Srivastav, A.K., Kusui, T., Ejiri, S., Chen, W., Tabuchi, Y., Furusawa, Y., Kondo, T., Sasayama, Y. Nishiuchi, T., Nakano, M., Sakamoto, T., Suzuki, N., 2012. Prostaglandin E $E_{2}$ increases both osteoblastic and osteoclastic activities in the scales of goldfish and participates in the calcium metabolism in goldfish. Zool. Sci., 29, 499-504.

Persson, P., Takagi, Y., Björnsson, B.Th., 1995. Tartrate resistant acid phosphatase as a marker for scale resorption in rainbow trout, Oncorhynchus mykiss: effects of estradiol$17 \beta$ treatment and refeeding. Fish Physiol. Biochem., 14, 329-339.

Petersen, T. N., Brunak, S., von Heijne G., Nielsen, H., 2011. SignalP 4.0: discriminating signal peptides from transmembrane regions. Nature Methods 8, 785-786.

Redruello, B., Estevao, M.D., Rotllant, J., Guerreiro, P.M., Anjos, L.I., Canario, A.V.M., Power, D.M., 2005. Isolation and characterization of piscine osteonectin and down regulation of its expression by PTH-related protein. J. Bone Miner. Res., 20, 682-692.

Sasayama, Y., 1999. Hormonal control of Ca homeostasis in lower vertebrates: considering the evolution. Zool. Sci., 16, 857-869. 
Sekiguchi, T., Suzuki, N., Fujiwara, N., Aoyama, M., Kawada, T., Sugase, K., Murata, Y., Sasayama, Y., Ogasawara, M., Satake, H., 2009. Calcitonin in a protochordate, Ciona intestinalis: the prototype of the vertebrate Calcitonin/Calcitonin gene related peptide superfamily. FEBS J. 276, 4437-4447.

Sekiguchi, T., Kuwasako, K., Ogasawara, M., Takahashi, H., Matsubara, S., Osugi, T., Muramatsu, I., Sasayama, Y., Suzuki, N., Satake, H., 2016. Evidence for conservation of the calcitonin superfamily and activity-regulating mechanisms in the basal chordate Branchiostoma floridae: insights into the molecular and functional evolution in chordates. J. Biol. Chem. 291, 2345-2356.

Suzuki, N., Nose, Y., Kase, Y., Sasayama, Y., Takei, Y., Nagasawa, H., Watanabe, T. X., Nakajima, K., Sakakibara, S., 1994. Amino acid sequence of sardine calcitonin and its hypocalcemic activity in rats. Zool. Sci. 11, 713-716.

Suzuki, N., Ueda, K., Sakamoto, H., Sasayama, Y., 1999. Fish calcitonin genes: primitive bony fish genes have been conserved in some lower vertebrates. Gen. Comp. Endocrinol., 113, 369-373.

Suzuki, N., Suzuki, T., Kurokawa, T., 2000. Suppression of osteoclastic activities by calcitonin in the scales of goldfish (freshwater teleost) and nibbler fish (seawater teleost). Peptides. 21, 115-124.

Suzuki, N., Hattori, A., 2002. Melatonin suppresses osteoclastic and osteoblastic activities in the scales of goldfish. J. Pineal Res. 33, 253-258.

Suzuki, N., Hattori, A., 2003. Bisphenol A suppresses osteoclastic and osteoblastic activities in the cultured scales of goldfish. Life Sci. 73, 2237-2247. 
Suzuki, N., Kambegawa, A., Hattori, A., 2003. Bisphenol A influences the plasma calcium level and inhibits calcitonin secretion in goldfish. Zool. Sci. 20, 745-748.

Suzuki, N., Yamamoto, K., Sasayama, Y., Suzuki, T., Kurokawa, T., Kambegawa, A., Srivastav, A.K., Hayashi, S., Kikuyama, S., 2004. Possible direct induction by estrogen of calcitonin secretion from ultimobranchial cells in the goldfish. Gen. Comp. Endocrinol. $138,121-127$.

Suzuki, N., Kitamura, K., Nemoto, T., Shimizu, N., Wada, S., Kondo, T., Tabata, M.J., Sodeyama, F., Ijiri, K., Hattori, A., 2007. Effect of vibration on osteoblastic and osteoclastic activities: analysis of bone metabolism using goldfish scale as a model for bone. Adv. Space Res. 40, 1711-1721.

Suzuki, N., Somei, M., Seki, A., Reiter, R.J., Hattori, A., 2008. Novel bromomelatonin derivatives as potentially effective drugs to treat bone diseases. J. Pineal Res., 45, 229-234.

Suzuki, N., Kitamura, K., Omori, K., Nemoto, T., Satoh, Y., Tabata, M.J., Ikegame, M., Yamamoto, T., Ijiri, K., Furusawa, Y., Kondo, T., Takasaki, I., Tabuchi, Y., Wada, S., Shimizu, N., Sasayama, Y., Endo, M., Takeuchi, T., Nara, M., Somei, M., Maruyama, Y., Hayakawa, K., Shimazu, T., Shigeto, Y., Yano, S. and Hattori, A., 2009. Response of osteoblasts and osteoclasts in regenerating scales to gravity loading. Biol. Sci. Space 23, 211-217.

Suzuki, N., Danks, J.A., Maruyama, Y., Ikegame, M., Sasayama, Y., Hattori, A., Nakamura, M., Tabata, M.J., Yamamoto, T., Furuya, R., Saijoh, K., Mishima, H., Srivastav, A.K., Furusawa, Y., Kondo, T., Tabuchi, Y., Takasaki, I., Chowdhury, V.S., Hayakawa, K., Martin, T.J., 2011. Parathyroid hormone 1 (1-34) acts on the scales and involves calcium metabolism in goldfish. Bone 48, 1186-1193. 
Tamura, K., Stecher, G., Peterson D., Filipski, A., Kumar, S., 2013. MEGA6: molecular evolutionary genetics analysis version 6.0. Mol. Biol. Evol., 30, 2725-2729.

Thamamongood, T.A., Furuya, R., Fukuba, S., Nakamura, M., Suzuki, N., Hattori, A., 2012. Expression of osteoblastic and osteoclastic genes during spontaneous regeneration and autotransplantation of goldfish scale: a new tool to study intramembranous bone regeneration. Bone 50, 1240-1249.

Tinsley, D., 1985. A comparison of plasma levels of phosphoprotein, total protein and total calcium as indirect indices of exogenous vitellogenesis in the crucian carp, Carassius carassius (L.). Comp. Biochem. Physiol., Part B 80, 913-916.

Yamauchi, H., Orimo, H., Yamauchi, K., Takano, K., Takahashi, H., 1978. Increased calcitonin levels during ovarian development in the eel, Anguilla japonica. Gen. Comp. Endocrinol., 36, 526-529.

Yoshikubo, H., Suzuki, N., Takemura, K., Hoso, M., Yashima, S., Iwamuro, S., Takagi, Y., Tabata, M.J., Hattori, A., 2005. Osteoblastic activity and estrogenic response in the regenerating scale of goldfish, a good model of osteogenesis. Life Sci., 76, 2699-2709.

Watts, E.G., Copp, D.H., Deftos, L.J., 1975. Changes in plasma calcitonin and calcium during the migration of salmon. Endocrinology, 96, 214-218. 


\section{Figure legends}

Fig. 1. Nucleotide and deduced amino-acid sequences of sardine preprocalcitonin

The deduced amino acid sequence of preprocalcitonin is depicted under the preprocalcitonin cDNA sequence. The signal peptide, N-proCT, CT, and C-proCT are shown by the dotted underline, box, double underline, and underline, respectively. The stop codon TGA is indicated by an asterisk. This data is available under GenBank accession number LC191399.

Fig. 2. Multiple alignments of the amino-acid sequences of N-proCTs Identical amino acids are shown in black boxes. DDBJ/EMBL/GenBank accession numbers are as follows: Japanese medaka, NP_001098365; fugu, CAC81278; Atlantic salmon, NP_001135058; green sea turtle, EMP38282; American alligator, XP_006275102; rock pigeon, EMC88082; chicken , ABY65359; African ostrich, XP_009683015; turkey, XP_003206284; platypus, ENSOANP00000017830; Tasmanian devil, XP_003773616; ninebanded armadillo, XP_004472573; cattle, NP_001137209; domestic cat, BAO79719; horse, AAF72526; human, AAA58403; rhesus monkey, EHH23079; house mouse, P70160; and Norway rat, AAA40849.

Fig. 3. Phylogenetic tree of CTs and N-proCTs

Phylogenetic trees of CTs (A) and N-proCTs (B) were calculated by the neighbor-joining method. The bootstrap value is shown besides each branch as the percentage of times. The scale bars show an evolutionary distance of 0.1 and 0.05 amino acid substitutions per protein. 
Fig. 4. Effects of sardine CT (A) and sardine N-proCT (B) on ALP activities in cultured scales incubated for $6 \mathrm{~h}$

** indicates a statistically significant difference at $p<0.01$ from the values of control scales $(n=8)$.

Fig. 5. Effects of sardine CT (A) and sardine N-proCT (B) on TRAP activities in cultured scales incubated for $6 \mathrm{~h}$

$*$, **, and $* * *$ indicate statistically significant differences at $p<0.05, p<0.01$, and $p<0.001$, respectively, from the values of control scales $(n=8)$.

Fig. 6. Effects of sardine CT and sardine N-proCT on type 1 collagen (A: CT; B: N-proCT) and osteocalcin (C: CT; D: N-proCT) mRNA expressions in cultured scales incubated for $6 \mathrm{~h}$ $*$ and $* *$ indicate statistically significant differences at $p<0.05$ and $p<0.01$, respectively. $\mathrm{n}=9$ samples; one sample from one fish.

\section{Table legend}

Table 1. Similarity of sardine CT, sardine N-proCT, and sardine C-proCT to those of other vertebrates 


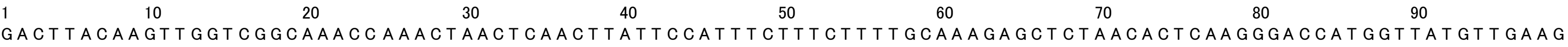

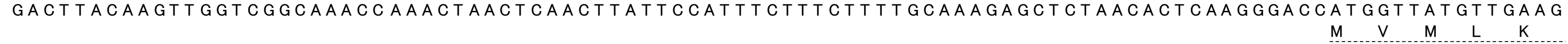

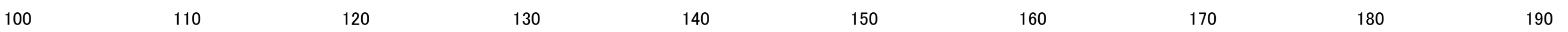

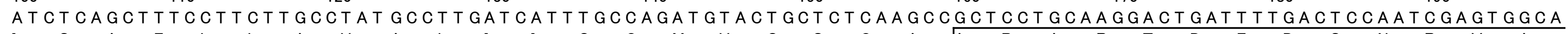

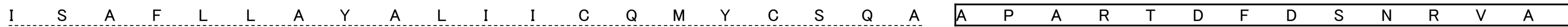

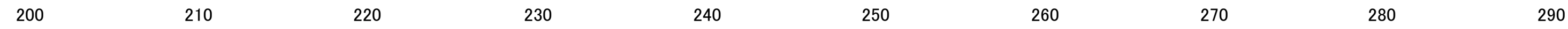

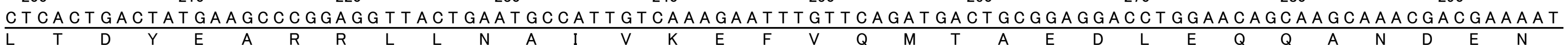

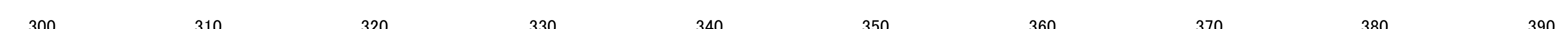

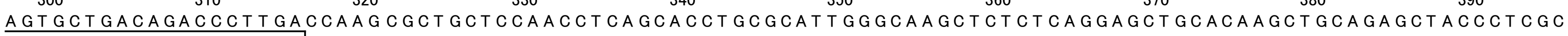

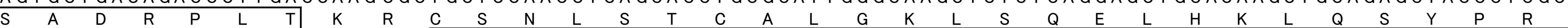
400 420

430

450

460

470

480

490

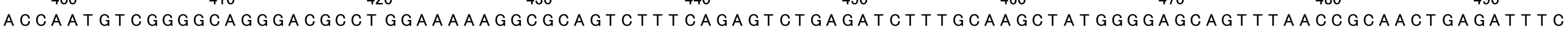
$\begin{array}{llllllllllllllllllllllllllllllll}T & N & V & G & A & G & T & P & G & K & R & R & S & L & S & E & S & E & I & F & A & S & Y & G & E & Q & F & N & R & =N\end{array}$

500

520

530

550

560

570

580

590

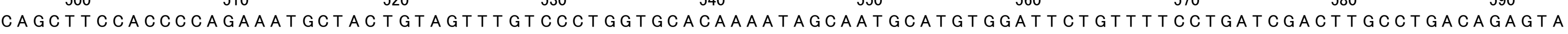

600

610

620

630

640

650

660

670

680

690

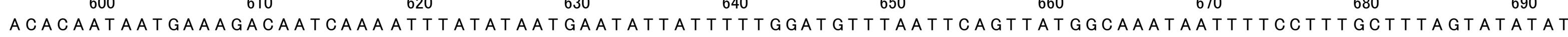

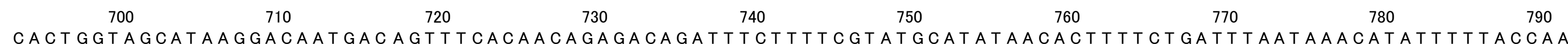
800 810

T A A A A A A A A A A A A A A A A A

Figure 1 Kase et al. 
Japanese sardine

Japanese medaka

Fugu

Atlantic salmon

Green sea turtle

American alligator

Rock pigeon

Chicken

African ostrich

Turkey

Platypus

Tasmanian devil

Nine-banded armadillo

Cattle

Domestic cat

Horse

Human

Rhesus monkey

House mouse

Norway rat

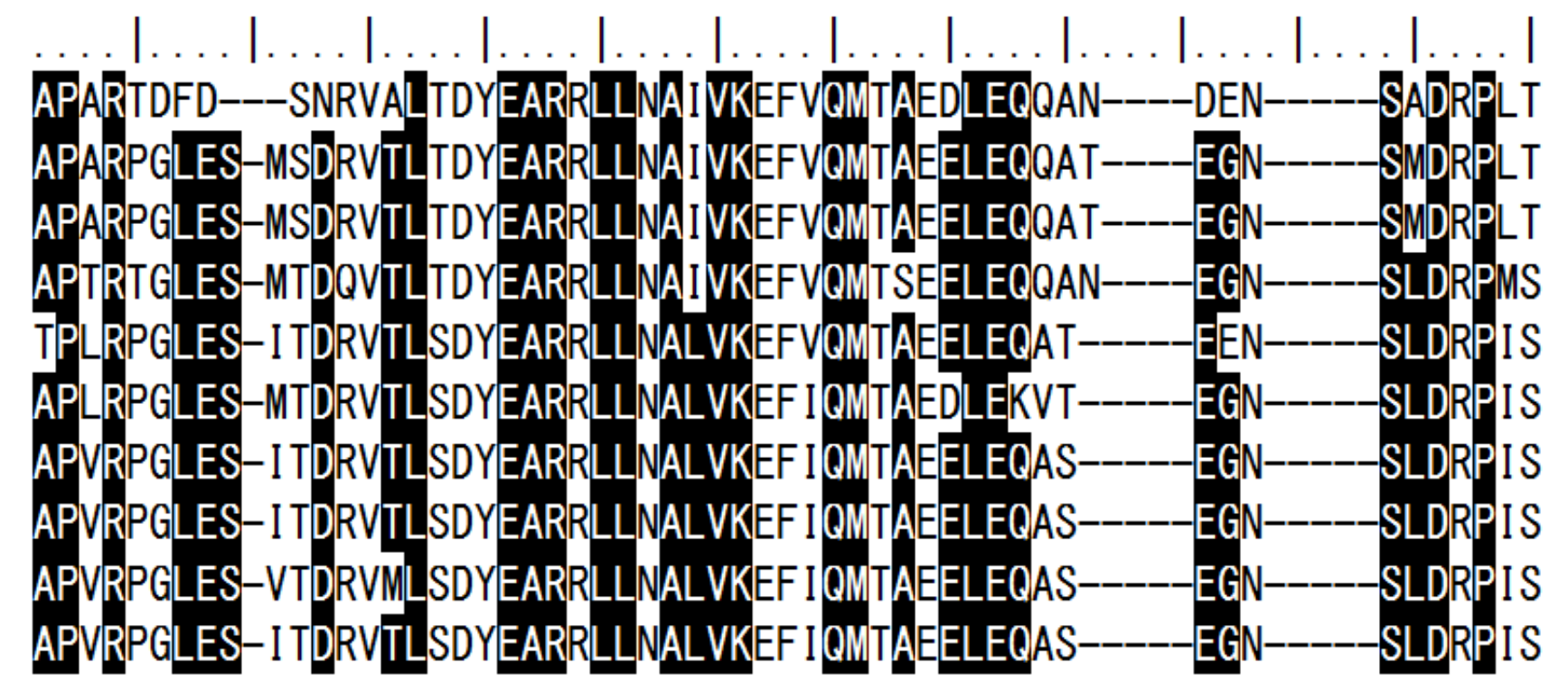

APLRPGFES-IADRVTLNDDEARRLLNALVKEFVOMKTEELEQMT-----EGDRFFPRSLDRPIS

APFRPGFESVMPDHVALSDEEARHLLINALVKEFVQMKKADELDQVVT----_EDN-----SLDRPRA

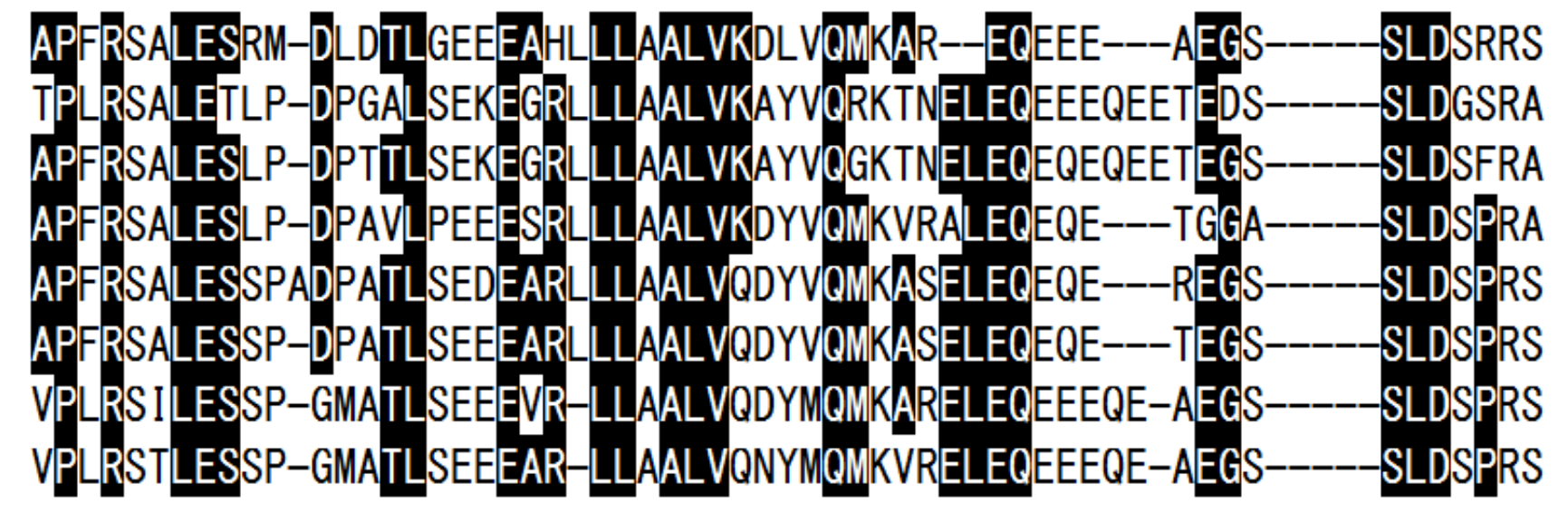

Figure 2 Kase et al. 
(A) Phylogenetic tree of CTs

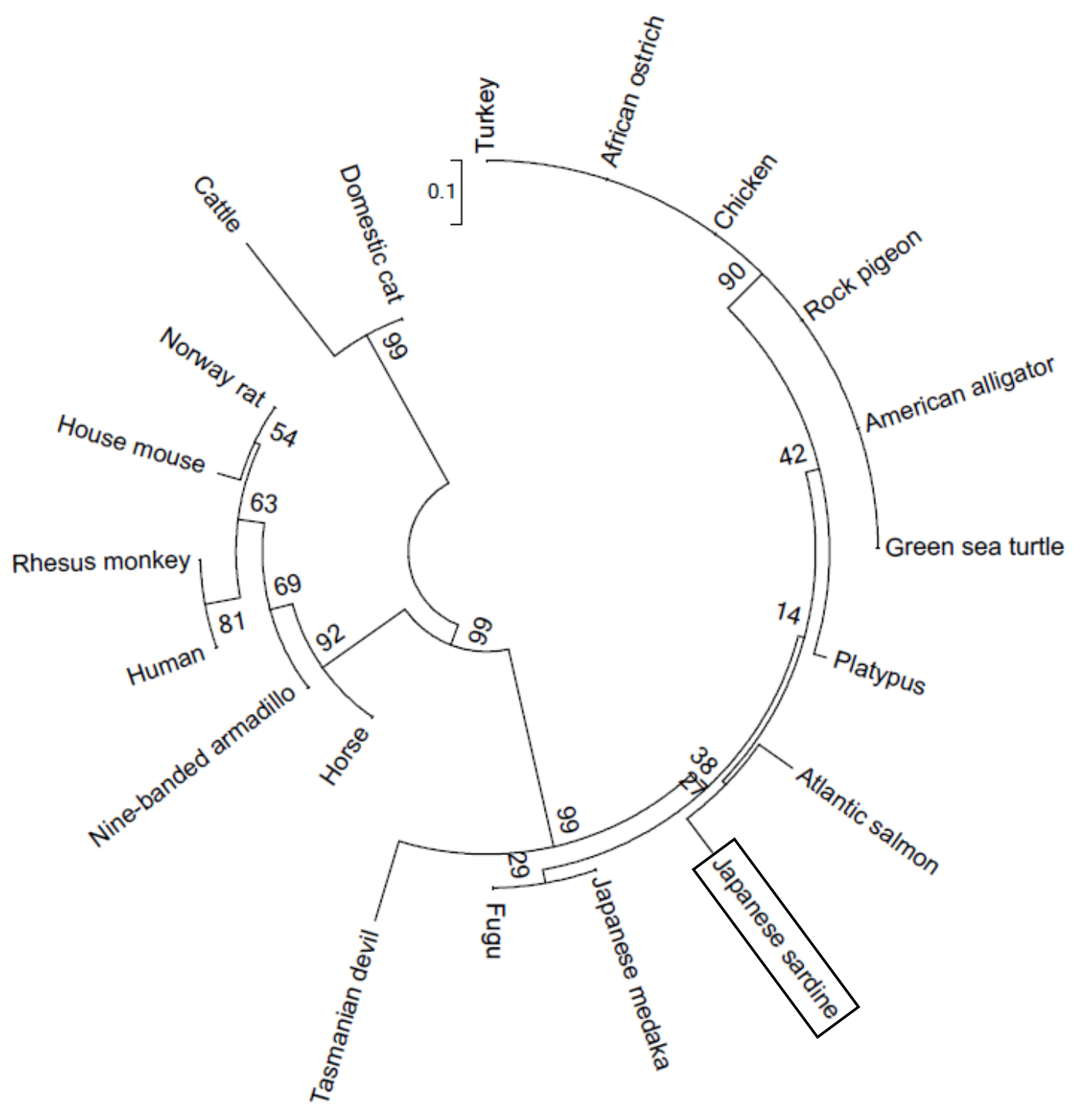

(B) Phylogenetic tree of N-proCTs

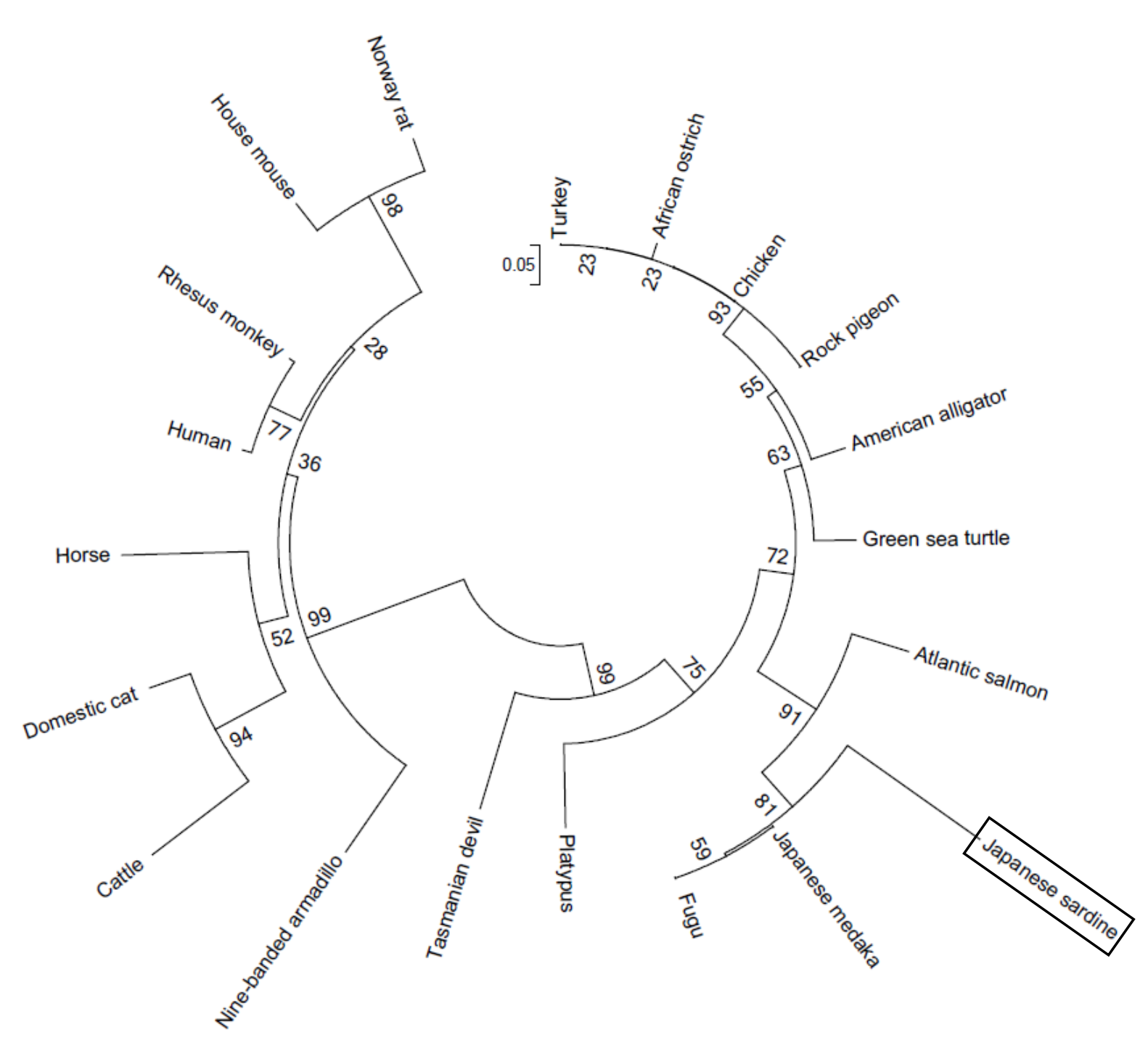

Figure 3 Kase et al. 


\section{(A) $\mathrm{CT}$}

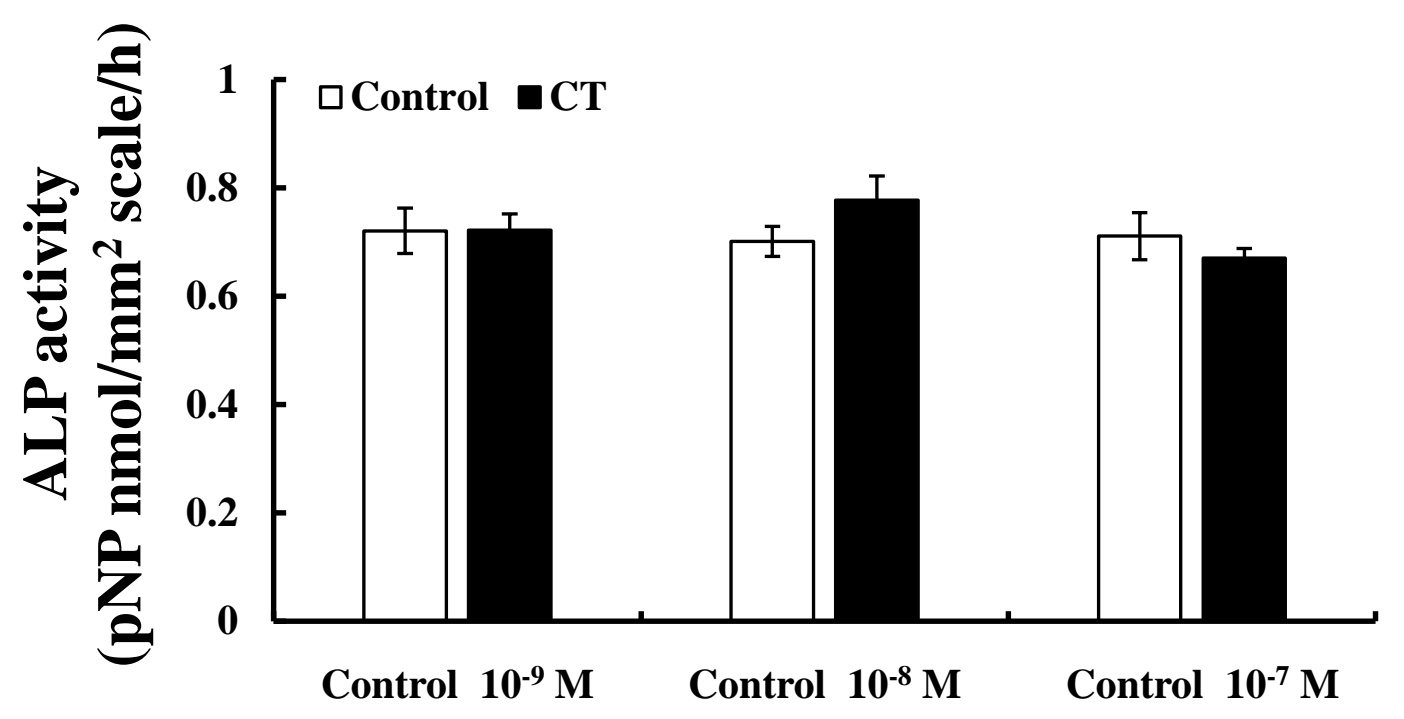

(B) N-proCT

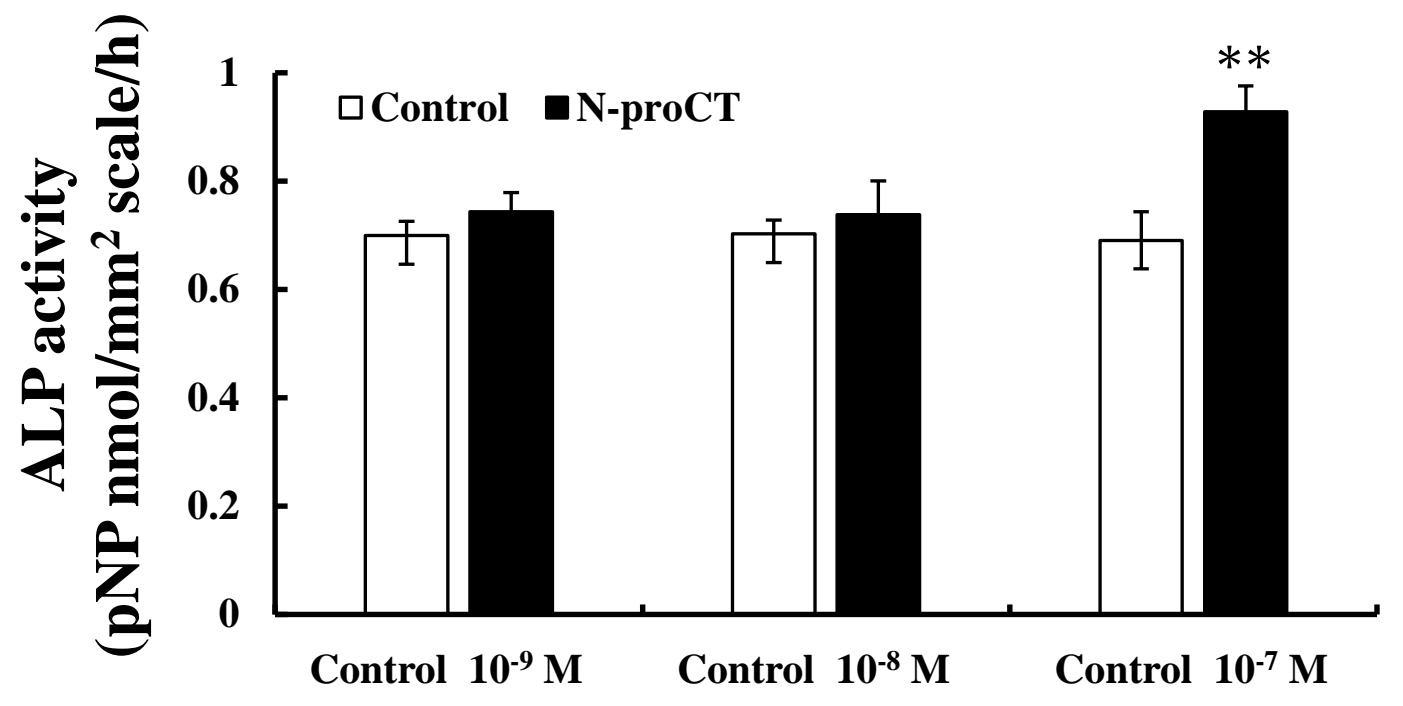

Figure 4 Kase et al. 


\section{(A) $\mathrm{CT}$}

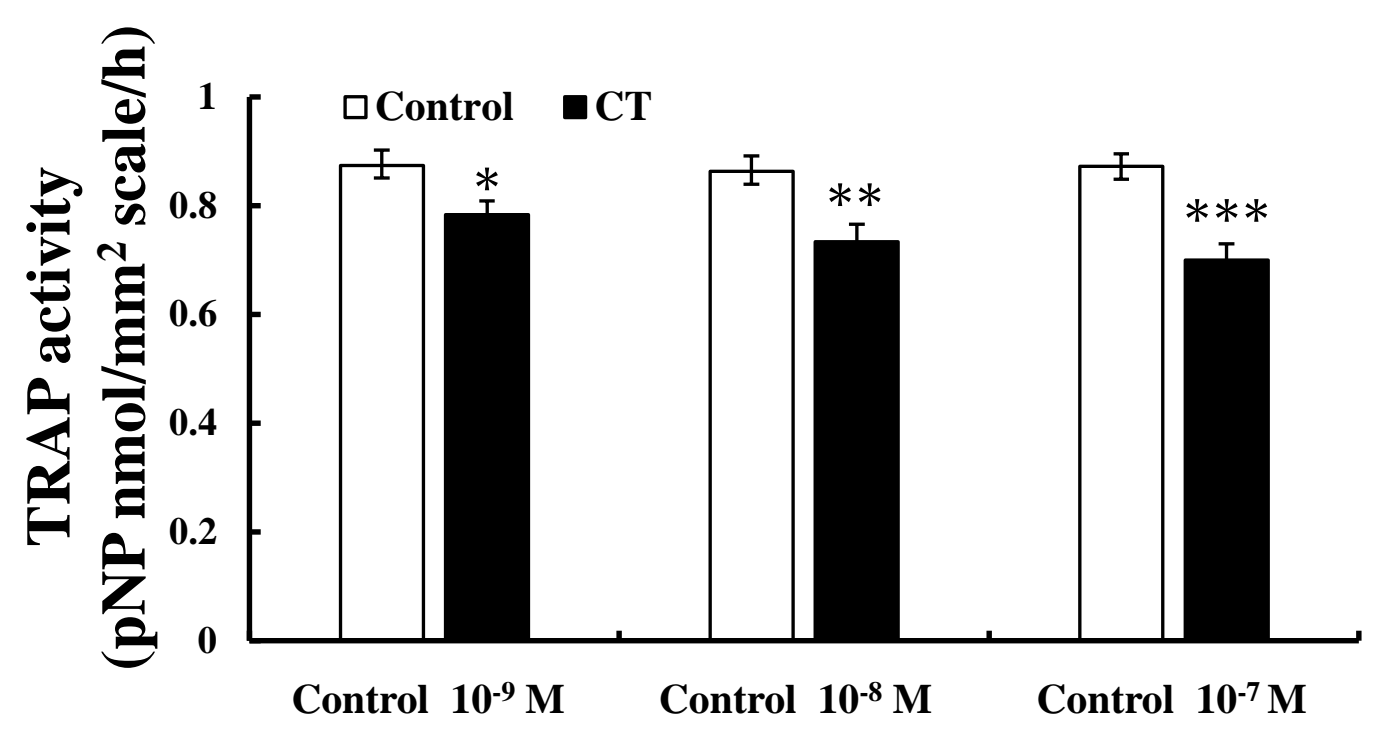

(B) N-proCT

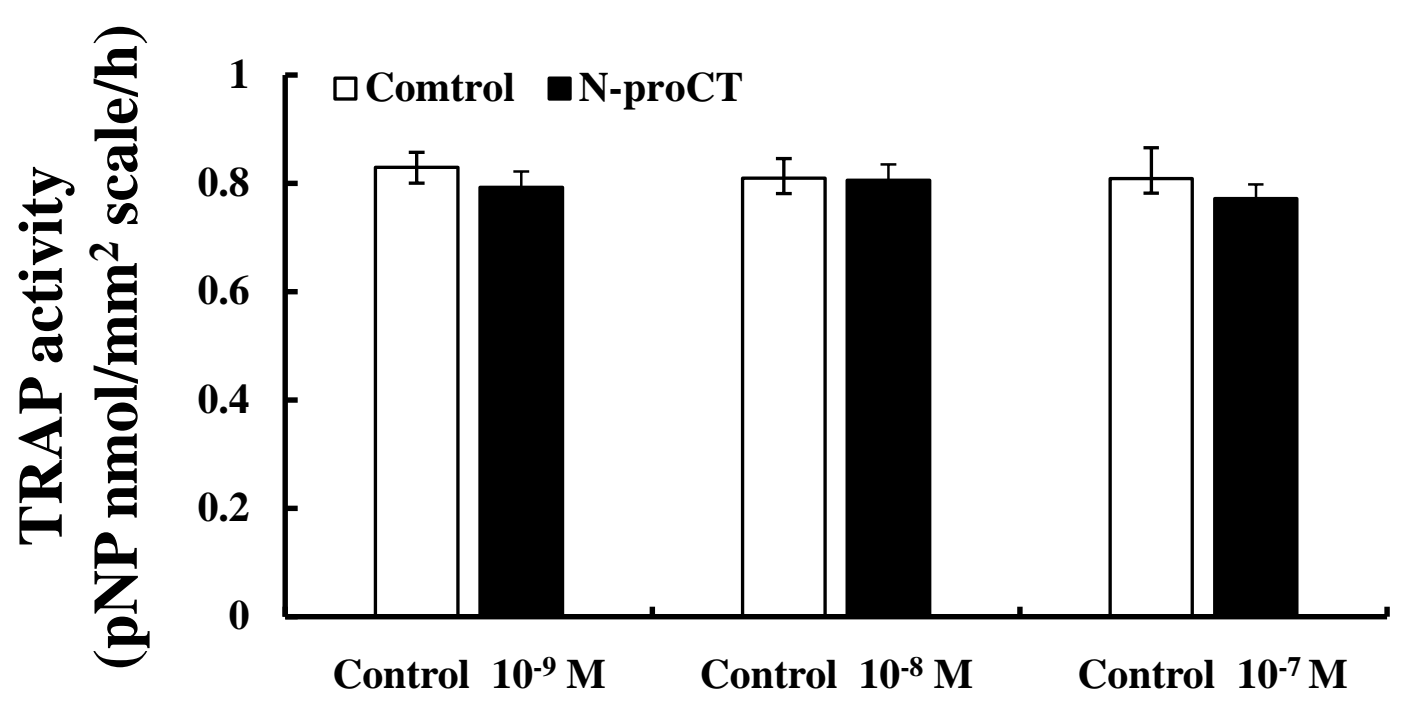

Figure 5 Kase et al. 
(A)

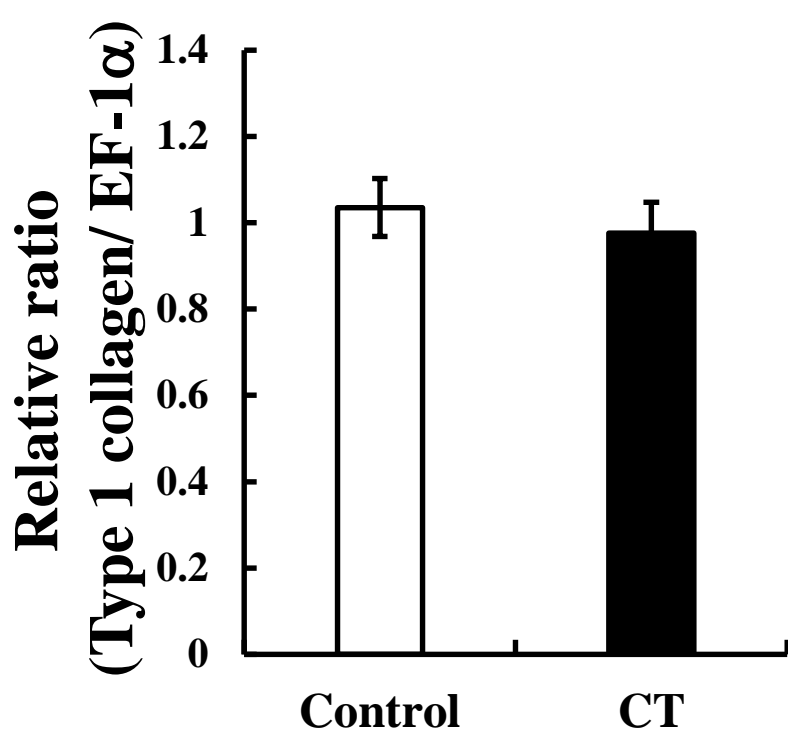

(B)

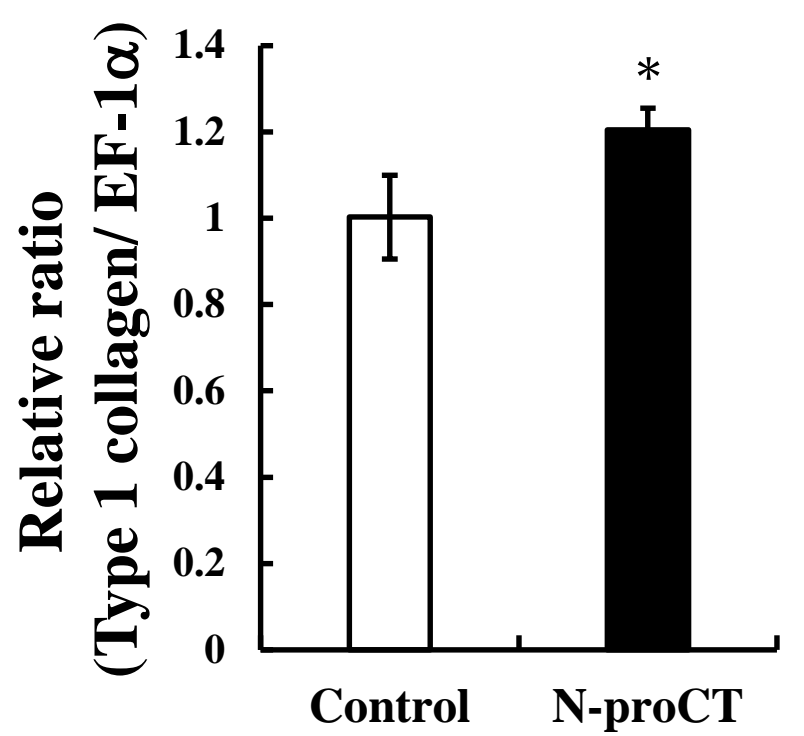

(C)

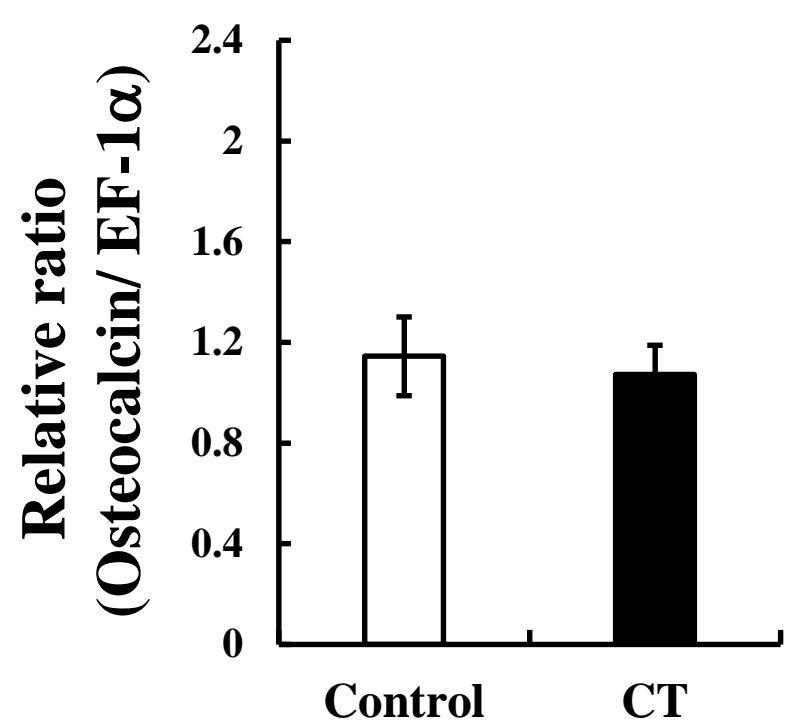

(D)

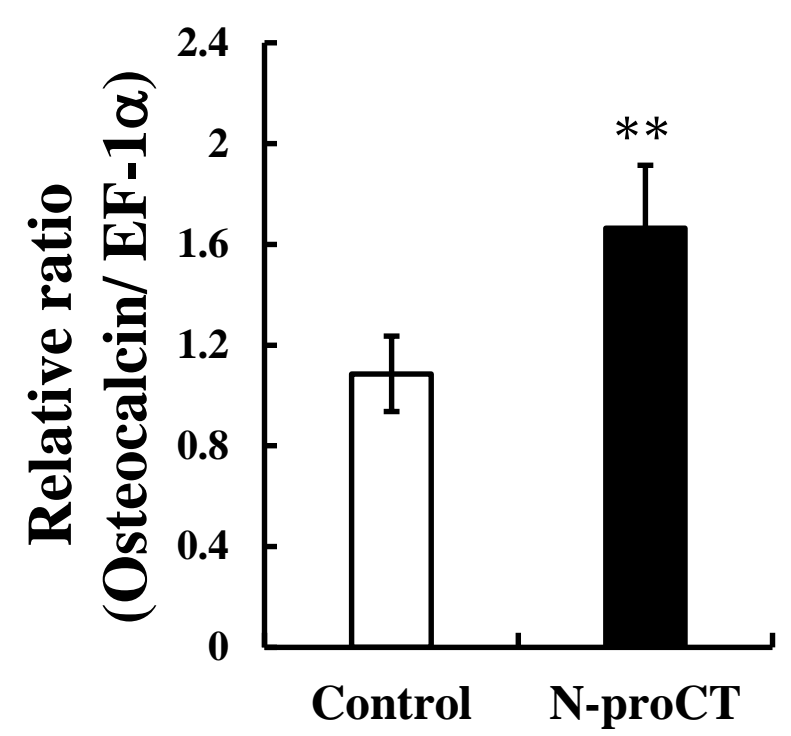


Table 1. Similarity of sardine CT, sardine N-proCT, and sardine C-proCT to those of other vertebrates.

\begin{tabular}{|c|c|c|c|c|c|}
\hline Animal & Scientific name & $\begin{array}{c}\text { Similarity of } \\
\text { CT(\%) }\end{array}$ & $\begin{array}{l}\text { Similarity of } \\
\text { N-proCT (\%) }\end{array}$ & $\begin{array}{l}\text { Similarity of } \\
\text { C-proCT (\%) }\end{array}$ & Accession \\
\hline Japanese sardine & Sardinops melanostictus & $100.0 \%$ & $100.0 \%$ & $100.0 \%$ & LC191399 \\
\hline Japanese medaka & Oryzias latipes & $96.9 \%$ & $83.6 \%$ & $66.7 \%$ & NP_001098365 \\
\hline Fugu & Takifugu rubripes & $96.9 \%$ & $83.6 \%$ & $72.2 \%$ & CAC81278 \\
\hline Atlantic salmon & Salmo salar & $93.8 \%$ & $85.5 \%$ & $66.7 \%$ & NP_001135058 \\
\hline Green sea turtle & Chelonia mydas & $96.9 \%$ & $78.2 \%$ & $57.1 \%$ & EMP38282 \\
\hline American alligator & Alligator mississippiensis & $96.9 \%$ & $78.2 \%$ & $57.1 \%$ & XP_006275102 \\
\hline Rock pigeon & Columba livia & $96.9 \%$ & $80.0 \%$ & $52.4 \%$ & EMC88082 \\
\hline Chicken & Gallus gallus & $96.9 \%$ & $80.0 \%$ & $52.4 \%$ & ABY65359 \\
\hline African ostrich & Struthio camelus & $96.9 \%$ & $80.0 \%$ & $47.6 \%$ & XP_009683015 \\
\hline Turkey & Meleagris gallopavo & $96.9 \%$ & $80.0 \%$ & $52.4 \%$ & XP_003206284 \\
\hline Platypus & Ornithorhynchus anatinus & $93.8 \%$ & $66.7 \%$ & $57.1 \%$ & ENSOANP00000017830 \\
\hline Tasmanian devil & Sarcophilus harrisii & $87.5 \%$ & $69.6 \%$ & $42.9 \%$ & XP_003773616 \\
\hline Nine-banded armadillo & Dasypus novemcinctus & $71.9 \%$ & $50.9 \%$ & $33.3 \%$ & XP_004472573 \\
\hline Cattle & Bos taurus & $50.0 \%$ & $50.0 \%$ & $38.1 \%$ & NP_001137209 \\
\hline Domestic cat & Felis catus & $62.5 \%$ & $48.3 \%$ & $14.3 \%$ & BAO79719 \\
\hline Horse & Equus caballus & $75.0 \%$ & $50.9 \%$ & $28.6 \%$ & AAF72526 \\
\hline Human & Homo sapiens & $68.8 \%$ & $63.2 \%$ & $19.0 \%$ & AAA58403 \\
\hline Rhesus monkey & Macaca mulatta & $68.8 \%$ & $61.4 \%$ & $23.8 \%$ & EHH23079 \\
\hline House mouse & Mus musculus & $71.9 \%$ & $54.2 \%$ & $33.3 \%$ & P70160 \\
\hline Norway rat & Rattus norvegicus & $75.0 \%$ & $52.5 \%$ & $28.6 \%$ & AAA40849 \\
\hline
\end{tabular}

